\title{
Analysis of spatio-temporal changes in forest biomass in China
}

\author{
Weiyi Xu ${ }^{1,2} \cdot$ Xiaobin Jin ${ }^{1,2,3} \cdot$ Jing Liu ${ }^{1,2}$. \\ Xuhong Yang ${ }^{1,2} \cdot$ Jie Ren $^{1,2} \cdot$ Yinkang Zhou ${ }^{1,2,3}$
}

Received: 17 June 2020 / Accepted: 6 October 2020 / Published online: 9 April 2021

(C) The Author(s) 2021

\begin{abstract}
Forests play a central role in the global carbon cycle. China's forests have a high carbon sequestration potential owing to their wide distribution, young age and relatively low carbon density. Forest biomass is an essential variable for assessing carbon sequestration capacity, thus determining the spatio-temporal changes of forest biomass is critical to the national carbon budget and to contribute to sustainable forest management. Based on Chinese forest inventory data (1999-2013), this study explored spatial patterns of forest biomass at a grid resolution of $1 \mathrm{~km}$ by applying a downscaling method and further analyzed spatiotemporal changes of biomass at different spatial scales. The main findings are: (1) the regression relationship between
\end{abstract}

Project funding: The work was supported by the National Key Research and Development Program of China (2019YFA0606603), the National Natural Science Foundation of China (No.41971234), and the Project of Graduate Student Innovative and Practical Research in Jiangsu Province (KYCX20-0028).

The online version is available at http://www.springerlink.com.

Corresponding editor: Yu Lei.

Supplementary information The online version contains supplementary material available at (https://doi.org/10.1007/ s11676-021-01299-8).

Xiaobin Jin

Jinxb@nju.edu.cn

1 School of Geography and Ocean Sciences, Nanjing University, Nanjing 210023, People's Republic of China

2 Key Laboratory of Coastal Zone Exploitation and Protection, Ministry of Land and Resources, Nanjing 210023, People's Republic of China

3 Natural Resources Research Center, Nanjing University, Nanjing 210023, People's Republic of China forest biomass and the associated influencing factors at a provincial scale can be applied to estimate biomass at a pixel scale by employing a downscaling method; (2) forest biomass had a distinct spatial pattern with the greatest biomass occurring in the major mountain ranges; (3) forest biomass changes had a notable spatial distribution pattern; increase (i.e., carbon sinks) occurred in east and southeast China, decreases (i.e., carbon sources) were observed in the northeast to southwest, with the largest biomass losses in the Hengduan Mountains, Southern Hainan and Northern Da Hinggan Mountains; and, (4) forest vegetation functioned as a carbon sink during 1999-2013 with a net increase in biomass of $3.71 \mathrm{Pg}$.

Keywords Forest vegetation biomass $\cdot$ Spatial distribution $\cdot$ Spatio-temporal changes

\section{Introduction}

Climate change characterized by global warming has been an international concern for many years (Bonan 2008; Fang et al. 2011, 2018; Austin et al. 2020). It is commonly accepted that greenhouse gas emissions, especially carbon dioxide $\left(\mathrm{CO}_{2}\right)$, are the major cause of global warming (Fang 2000; Quere et al. 2016; Chen et al. 2018; Xu et al. 2018a). Atmospheric $\mathrm{CO}_{2}$ levels have been increasing significantly as a result of urbanization, the increasing use of fossil fuels, and land- use changes (Lal 2008; Fang et al. 2011). Terrestrial ecosystems are significant carbon sinks, fixing atmospheric $\mathrm{CO}_{2}$ in vegetation and soil through photosynthesis. Sequestering $\mathrm{CO}_{2}$ into terrestrial ecosystems is considered to be one of the most cost-effective and environment-friendly way to reduce atmospheric $\mathrm{CO}_{2}$ concentrations (Piao et al. 2010; Tang et al. 2018). Forests are important for their 
potential to sequester carbon and to reduce $\mathrm{CO}_{2}$ concentrations and mitigate climate change (Wan et al. 2018; Liu and Sun 2019; Tarun et al. 2019). The amount of carbon that forests sequester annually accounts for more than two thirds of the total sequestered by all terrestrial ecosystems (Woodwell and Whittaker 1978; Zhao et al. 2013). Therefore forests play an important role in mitigating global warming and regulating the carbon cycle. Forest biomass refers to the total amount of dry matter made up of living organisms in a forest community at a point in time. It is an important quantitative characteristic of a forest ecosystem, both as an indicator of forest structure and quality and as a parameter in carbon accounting (Fang and Chen 2001; Kale and Roy 2012; Guo et al. 2013). A detailed assessment of the spatial and temporal variability of forest biomass is critical to create and maintain national sustainability policies related to climate change and it provides credible data for scientists and policy makers.

In 1876, Ebermeyer's calculation of branch, leaf, litter, and wood weight of several forest types in Germany was the earliest research on forest biomass (Ebermayer 1876). Since the 1950s, with increasing attention on the economic benefits of forests, the study of forest biomass has received more attention. Many developed countries have carried out comprehensive investigations on forest biomass (Remezon 1999). During the 1960s and 1970s, international research projects such as the International Biology Program (IBP) and Man and the Biosphere Program (MAB) furthered work in this area. Numerous researchers have studied the biomass of the world's major forest types and its spatial distribution characteristics, and have even estimated the total biomass of the Earth's biosphere (Dixon et al. 1994; FAO 2006). Studies of forest biomass began in the late 1970s in China. Initially, biomass estimation was conducted in field measurements for small-scale units such as plots (Li et al. 1981; Feng et al. 1982). The scale of studies has expanded from plots to a region and eventually globally, and research methods have been greatly diversified (Fang et al. 1996, 2001, 2007; Liu et al. 2020). Along with this advancement, numerous researchers have made significant contributions. Fang et al. (2001) established the continuous biomass expansion factor, BEF (the ratio of forest biomass to timber volume) using the data of biomass and China's forest inventory data for the last 50 years. They also structured the world's first time series biomass database for China, which has been deemed as a landmark and has been widely cited. Fang et al. (2018) are currently leading the project "Ecosystem Carbon Sequestration" that aims to systematically explore the carbon stocks and its distribution in China's terrestrial ecosystems. All this research has fully demonstrated the important role of China's forests to the global carbon cycle.

Owing to the distinct spatial heterogeneity of biomass, and the discrepancies among methods of measuring that are in use, considerable uncertainty exists in estimating forest biomass (Guo et al. 2010; Liu et al. 2012a). At present, there are four main methods for estimating biomass. One is to measure average biomass through field sampling of individual trees and field measurement and weighing, and then apply to the entire forest area to obtain the biomass. Despite its long track record and theoretical foundations, field sampling of trees is difficult to apply to a large area due to its logistical requirements and high cost (Li et al. 1981; Feng et al. 1982; Huang et al. 2016). Another method is to build relative growth models for biomass based on mathematical relationships between biomass and combination surrogate predictors such as stem diameter, height, age or vegetation types (Fang et al. 1996; Li et al. 2011a, b), and apply them to individual trees or to plots in a forest inventory context. This method is widely-used but is limited by dependence on models of varying quality as well as by the resolution of the inventory dataset to which the models are applied. Another method is to calculate a biomass expansion factor (BEF) to convert stem volume to biomass based on inventory data, which is the mainstream method for estimating regional forest biomass including the mean BEF method and the continuous BEF method. The former is to use the average value of BEF of forest types to extract the biomass and the BEF is a constant. However, with in-depth studies, researchers have found that BEF is not a constant but changes with site conditions, forest age and stand density. Therefore, forest biomass should be calculated using the variable BEF (Fang et al. 2001, 2007). Fang et al. (2001) found that the BEF can be expressed as a consistent function of stem volume no matter how the forest ages, or how site conditions and stand density change. Based on field measurements, they developed a simple reciprocal equation to represent the relationship between BEF and volume of a particular forest type, i.e., $B E F=a+b / x$, where $x$ is the timber volume per unit area and $a$ and $b$ are constants for a forest type. This is the continuous BEF method. Therefore, biomass can be calculated according to the corresponding area and volume data in the forest inventory, and this method realizes the transformation of biomass from field measurement to regional-scale calculation. However, owing to the statistical units of forest inventory data that are mostly administrative regions (cities and provinces), the BEF method is mainly used to estimate forest biomass at the regional scale, which is difficult to carry out biomass estimations at a fine scale (pixels) and to explore spatial patterns. The fourth method is to construct models of biomass as a function of wall-to-wall geospatial data such as satellite imagery or attribute layers such as hydrology, climate and terrain. This method is often used to generate pixel-based estimates of biomass, and these can then be aggregated to generate summaries within userdefined areas. However, this method is highly restricted by the quality and accuracy of the data and the effectiveness of 
the key remote sensing parameters. Therefore, estimating forest biomass at the pixel scale cannot always fully effective by a simple remote sensing method (Li et al. 2011a, b; Wang et al. 2018).

Current estimation methods of forest biomass are currently based on inventory data suitable for biomass estimation at a regional scale. Due to the limitations of methods and data, it is difficult to obtain biomass data at a fine scale and to reflect spatial distribution characteristics. Furthermore, accuracy of biomass estimation by a single remote sensing method cannot be guaranteed. As a consequence, this study attempts to effectively combine field survey data with remote sensing and to find a method that not only reflects the advantages of remote sensing in spatial distribution, but also retains the reliability of field survey data so as to understand forest biomass estimation at a fine scale and reveal spatio-temporal changes.

In recent years, a downscaling method has been widely used in climatic and hydrological forecasting, the spatialization of populations and forest biomass (Liao and Li 2003; Wetterhall et al. 2005). It converts large-scale, coarse-resolution information (regional scale) into small-scale, fineresolution information (pixel scale) (Zhao and Xu 2007; Liu et al. 2012b). In addition, current research on forest biomass focuses more on estimation methods and spatial distribution, and less on spatio-temporal characteristics under a multispatial scale. With this in mind, combining Chinese forest inventory data from 1999 to 2013, remote sensing data, and climate and terrain data, this study quantitatively explores the spatial distribution of forest biomass (with a resolution of $1 \mathrm{~km}$ ) using a downscaling method, and further analyzed spatio-temporal biomass changes at different scales. This study provides a new perspective and method for forest biomass estimation on a more precise scale.

\section{Materials and methods}

\section{Study area}

China is a vast territory with numerous rivers and lakes, staggered mountain ranges, complex and diverse landforms, and differences in hydrothermal conditions in latitudinal, longitudinal and vertical zones. The country forms an intricate natural geographical environment with various forest communities with characteristics of numerous species and diverse forest types, providing a unique location to study forest biomass. In addition, China's forests play key roles in the world. According to the 8th forest inventory, total forest area is $20.77 \times 10^{7}$ ha, covering $21.6 \%$ of the county, and forest carbon stock is 15.14 billion $\mathrm{m}^{3}$. China ranks the 5 th in the world in forest area and the 6th in forest stock. Plantations are 69 million ha, ranking first in the world. The spatial pattern of forest area in 2010 (with a resolution of $1 \mathrm{~km}$ ) is shown in Fig. 1, and the data are from the database for land use remote sensing monitoring in China (http://www.resdc. $\mathrm{cn} /$ ) based on Landsat 8 and generated by artificial visual interpretation.

\section{Framework of the study}

The framework of this study is illustrated in Fig. 2 and the procedures are as follows:

(1) Based on Chinese forest inventory data 1999-2013, forest biomass was estimated at a provincial scale;

(2) A regression model was employed to establish statistical relationships between forest biomass and factors influencing it at a provincial scale. The relationship was then applied to estimate biomass at a pixel scale by the downscaling method; and,

(3) Spatial distribution and spatio-temporal changes of biomass were further analyzed at different spatial scales (national, provincial and pixel scales).

\section{Methods}

\section{Estimation of forest biomass at a provincial scale}

Forest inventories have been maintained and updated every five years by the State Forestry Administration. Individual provinces are treated as isolated investigation units (excluding Hong Kong, Taiwan and Macao). Through the permanent sample plot review $\left(41.5 \times 10^{4}\right.$ ground sample plots and $28.4 \times 10^{6}$ remote sensing sample plots), the quantity, quality and structure of forest resources as well as related factors (tree age, area, timber volume) reflecting the ecological status and functional benefits of forests were recorded. These records are systematic, considered reliable and used as the reference in China (Fang et al. 2001). In this study, three periods of forest inventory were included during 1999-2013, i.e., the 6th forest inventory (1999-2003), the 7th forest inventory (2004-2008) and the 8th forest inventory (2009-2013).

Based on the definition of forest inventory, forests were divided into three major types: forest stands (natural forests and plantations), economic forests (fruit, medicinal and seasoning species), and bamboo forests (Guo et al. 2013). However, the forest inventory provides different details for these forest types. For forest stands, it documents areas and volumes by dominant species in each province but only the areas for economic and bamboo forests. Therefore, the estimation of forest biomass in this study only focuses on the above mentioned three types of forest. 
Fig. 1 The study area

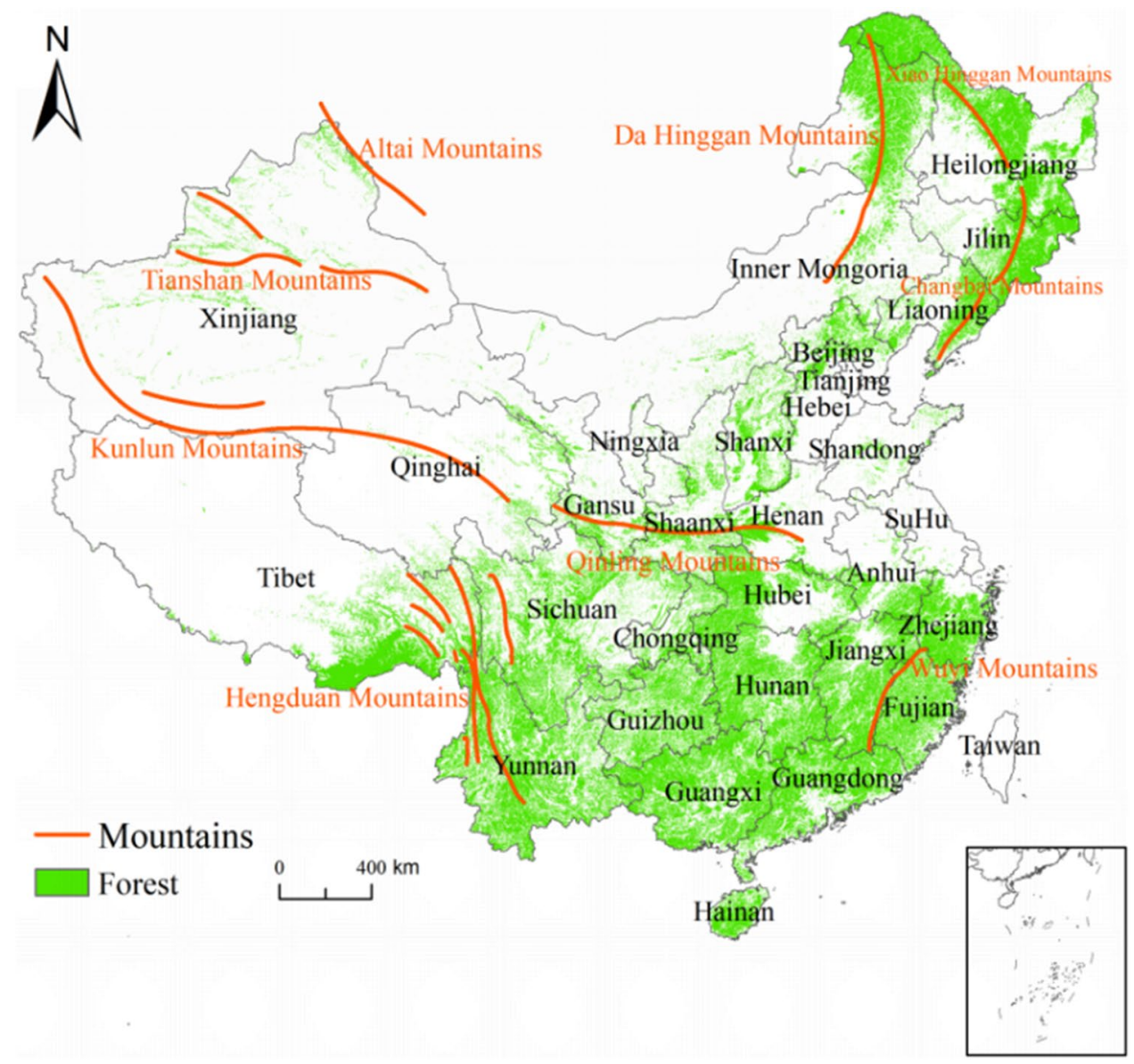

Previous studies have shown that the continuous BEF method was the optimum to estimate regional forest biomass, especially if there are sufficient forest inventory data (Fang and Wang 2001; Fang et al. 2002; Guo et al. 2010). Therefore, the biomass of forest stands for each inventory period was estimated by applying the continuous BEF method shown in Eq. 1.

$B E F=a+b / x$

where $B E F$ is the biomass expansion factor; $x$ is the volume per unit area $\left(\mathrm{m}^{3} \mathrm{ha}^{-1}\right) ; a$ and $\mathrm{b}$ are constants for a forest type, and the values of $a$ and $b$ are drawn from Fang et al. (1996, 2001, 2007) (see appendix Table S1).

Because the inventory data only document areas of economic and bamboo forests in each province, this study estimated the biomass of these areas by utilizing the mean biomass method (Eq. 2):

$B=\rho \times s$

where $B$ is the biomass of economic or bamboo forests $(\mathrm{t}) ; \rho$ is the mean biomass density $\left(\mathrm{t} \mathrm{ha}^{-1}\right.$ ) (Fang et al. 1996; Guo et al. 2013), the $\rho$ of the economic forests are $23.7 \mathrm{t} \mathrm{ha}^{-1}$, the moso bamboo forests $81.9 \mathrm{t} / \mathrm{ha}$, and other bamboo forests $53.1 \mathrm{tha}^{-1} ; s$ is the area of economic or bamboo forest (ha).

\section{Downscaling method}

\section{Selection of influencing factors}

Variations of temperature and precipitation directly affect the intensity of photosynthesis and respiration and the rate of accumulation of organic matter, thus affecting accumulation of biomass (Li et al. 2011a, b). Meanwhile, terrain factors (such as elevation, slope) have directly affect climatic factors such as temperature and precipitation in the region, which in turn leads to changes in forest types and the internal structure of forest vegetation, and indirectly affect accumulation of biomass (Xu et al. 2012). Furthermore, the normalized difference vegetation index (NDVI) can indicate vegetation cover conditions and reflect the dynamics of vegetation. It is widely applied in the study of land cover changes and quantitative inversion of biomass. Moreover, the significant correlation between NDVI and biomass has been widely acknowledged by scholars ( $\mathrm{Li}$ et al. 2014; Xu et al. 2018b). Thus, climate factors (i.e., temperature 


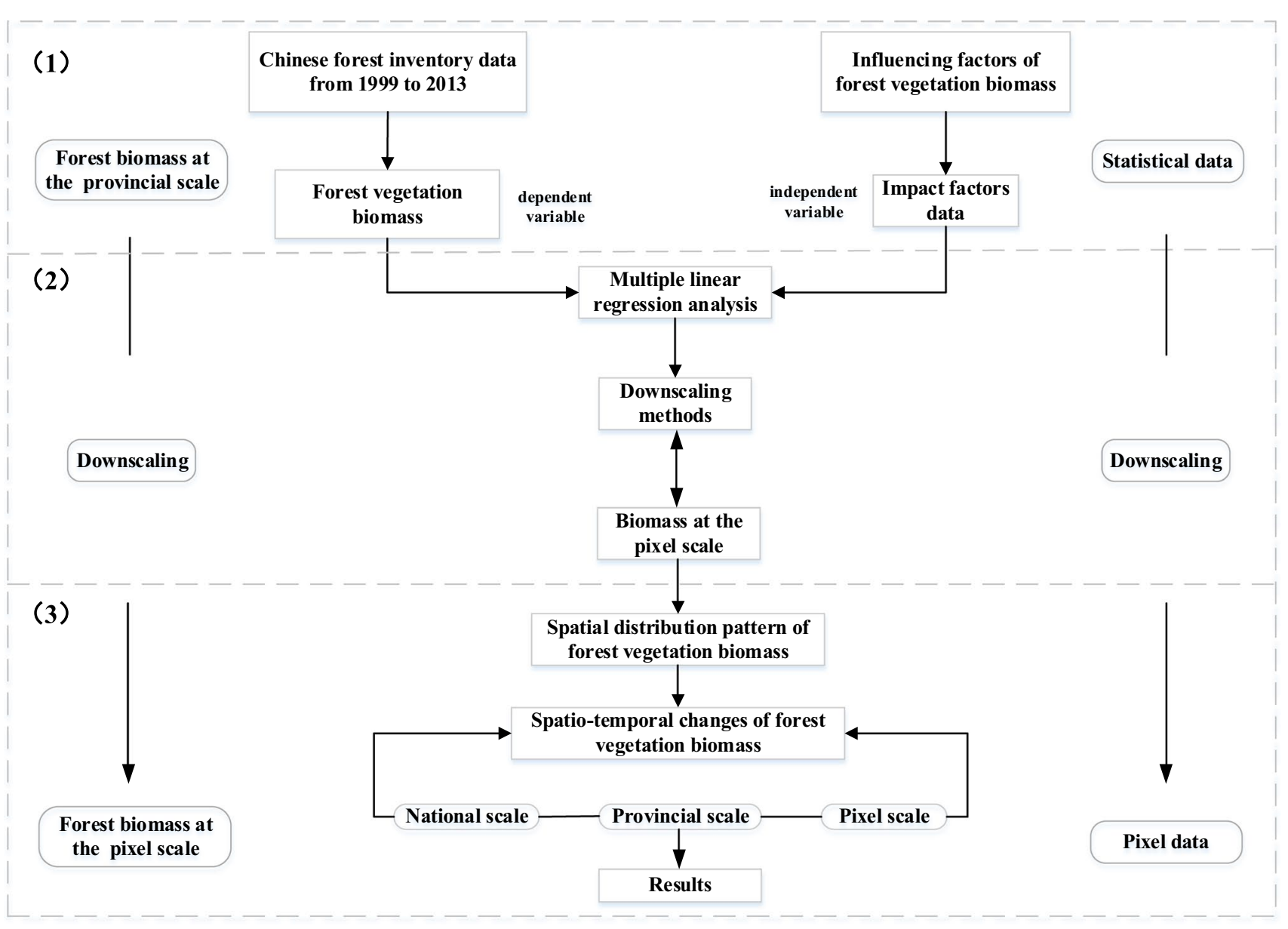

Fig. 2 Framework of this study

and precipitation), terrain factors (elevation and slope) and a vegetation factor (NDVI) were the influencing factors used in this study.

\section{Downscaling estimation}

To eliminate the impact of differences across data units, a greatest-value standardized method was employed before the multiple regression analysis to process data of both provincial impact factors and provincial forest vegetation biomass as shown in Eq. 3:

$r_{j}=x_{j} / x_{j \max }$

where, $r_{j}$ is the normalized value; $x_{j}$ is the actual value of the $j^{\text {th }}$ variable; $x_{\text {jmax }}$ is the maximum value of the $j^{\text {th }}$ variable.

A multiple linear regression analysis can be conducted with standardized provincial influencing factors and forest vegetation biomass as shown in Eq. 4:

$Y=a_{1} x_{1}+a_{2} x_{2}+a_{3} x_{3}+a_{4} x_{4}+a_{5} x_{5}+a_{6}$ where, $Y$ is the standardized value of provincial biomass; $x_{1}-x_{5}$ are the provincial standardized values for NDVI, temperature, precipitation, elevation and slope, respectively; and $a_{1}-a_{5}$ are the coefficient estimates of the regression model, with $a_{6}$ the constant.

Once all coefficient estimates are acquired, this regression model can be applied to pixels, as shown in Eq. 5, and all impact factors can be weighted along with their corresponding coefficients to obtain the weight of biomass at the pixel scale.

$S_{i j}=a_{1} x_{1 i j}+a_{2} x_{2 i j}+a_{3} x_{3 i j}+a_{4} x_{4 i j}+a_{5} x_{5 i j}+a_{6}$

where, $S_{i j}$ is the biomass weight for the $j^{\text {th }}$ pixel in the $i^{\text {th }}$ administrative region; $x_{1 i j}-x_{5 i j}$ are standardized values of NDVI, temperature, precipitation, elevation and slope of the $j^{\text {th }}$ pixel in the $i^{\text {th }}$ administrative region, respectively; and $a_{1}-a_{5}$ are the coefficient estimates of the regression model, with $a_{6}$ the constant. 
Based on the weight of biomass and the combined estimation of biomass at the provincial level by the forest inventory data, the biomass at pixel scale is obtained via Eq. 6:

$$
B i j=\frac{S i j}{\sum_{j=1}^{n} S i j} \times P i
$$

where, $B_{i j}$ represents the biomass of the $j^{t h}$ pixel in the $i^{t h}$ administrative region (t); $S_{i j}$ is the weight of biomass of the $j^{\text {th }}$ pixel in the $i^{\text {th }}$ administrative region; $n$ is the number of all pixels in $i^{t h}$ administrative region; $P_{i}$ is the estimated value of forest biomass in the $i^{\text {th }}$ province by the forest inventory data $(\mathrm{t})$.

\section{Verification of results}

According to the comparison of similarity studies, this study adopted the relative error $(R E)$ to verify the soundness of the provincial results of biomass estimation based on the continuous BEF method, and the biomass gridding results based on the downscaling method (Xu et al. 2018b). The calculation formula for $R E$ is:

$R E=\frac{\left|M_{1}-M_{2}\right|}{M_{2}} \times 100 \%$

where $M_{1}$ is the result obtained in this study; $M_{2}$ is the result derived from other studies.

\section{Data sources and preprocessing}

The sources of data used in this study are shown in Table 1.

Considering differences across data sources in terms of the spatial resolution, types of characteristics and the format, these data have been preprocessed to facilitate the subsequent analysis as follows: (1) project all spatial data into a unified Lambert projection coordinate system; resample all raster data to the resolution of $1 \mathrm{~km}$ via the nearest neighbor method, and extract the forest area from land use data. (2) employ the NDVI, temperature and precipitation data to generate five-year averaged data consistent with the forest inventory, and use DEM data to generate slope data; perform mask analysis between the influencing factor layers and forest area layers using ARCGIS 10.2 software's spatial analysis tools, and perform zonal statistics to combine mask analysis results and provincial administrative divisions to obtain the provincial statistics of the influencing factor.

\section{Results}

\section{Forest biomass at the provincial scale}

There were considerable differences in forest biomass in China during the study period (Fig. 3). Provinces with large biomass values were concentrated in the northeast (Heilongjiang, Jilin, Inner Mongolia) and the southwest (Tibet, Yunnan and Sichuan). Specifically for the $6^{\text {th }}$ forest inventory 1999-2003, the national total forest biomass was 12.34 $\mathrm{Pg}\left(1 \mathrm{Pg}=10^{9} \mathrm{t}\right.$ and $\left.1 \mathrm{Tg}=10^{6} \mathrm{t}\right)$. The largest biomass was in Heilongjiang (1.67 Pg) and accounted for $13.5 \%$ of the total biomass, followed by Tibet $(1.66 \mathrm{Pg})$ at $13.4 \%$. Biomass greater than $1 \mathrm{Pg}$ was recorded in the Heilongjiang, Inner Mongolia, Tibet, Yunnan and Sichuan provinces. The total biomass in the northeast (4.1 Pg) and southwest China (4.2 $\mathrm{Pg}$ ) was $8.3 \mathrm{Pg}$ and comprised $67 \%$ of the national total; for the 7th forest inventory 2004-2008, the national total was 14.26 $\mathrm{Pg}$ and higher than in the $6^{\text {th }}$ forest inventory. The largest biomass had switched to Tibet (1.77 Pg), accounting for $12.4 \%$ of the total, followed by Heilongjiang $(1.71 \mathrm{Pg})$

Table 1 Data sources of this study

\begin{tabular}{|c|c|c|c|}
\hline Types of data & Data names & Resolution/Scale & Data sources \\
\hline Forest statistical data & $\begin{array}{l}\text { Forest inventory data } \\
(1999-2003 ; 2004-2008 ; 2009-2013)\end{array}$ & - & $\begin{array}{l}\text { National forestry and } \\
\text { grassland data center } \\
\text { (http://www.fores } \\
\text { tdata.cn) }\end{array}$ \\
\hline Remote sensing data & $\begin{array}{l}\text { SPOT vegetation NDVI } \\
\text { data set in China (1999-2013) }\end{array}$ & $1 \mathrm{~km}$ & \\
\hline Land use data & Land use data in China $(2000 ; 2005 ; 2010)$ & $1 \mathrm{~km}$ & \\
\hline Terrain data & ASTER GDEM & $30 \mathrm{~m}$ & \\
\hline \multirow[t]{2}{*}{ Meteorological data } & $\begin{array}{l}\text { Annual average temperature } \\
(1999-2013)\end{array}$ & $500 \mathrm{~m}$ & $\begin{array}{l}\text { Resource and environ- } \\
\text { ment data cloud } \\
\text { platform (http:// } \\
\text { www.resdc.cn/) }\end{array}$ \\
\hline & $\begin{array}{l}\text { Annual average precipitation } \\
(1999-2013)\end{array}$ & $500 \mathrm{~m}$ & \\
\hline Administrative division & Chinese administrative division (2015) & $1: 400,0000$ & \\
\hline
\end{tabular}



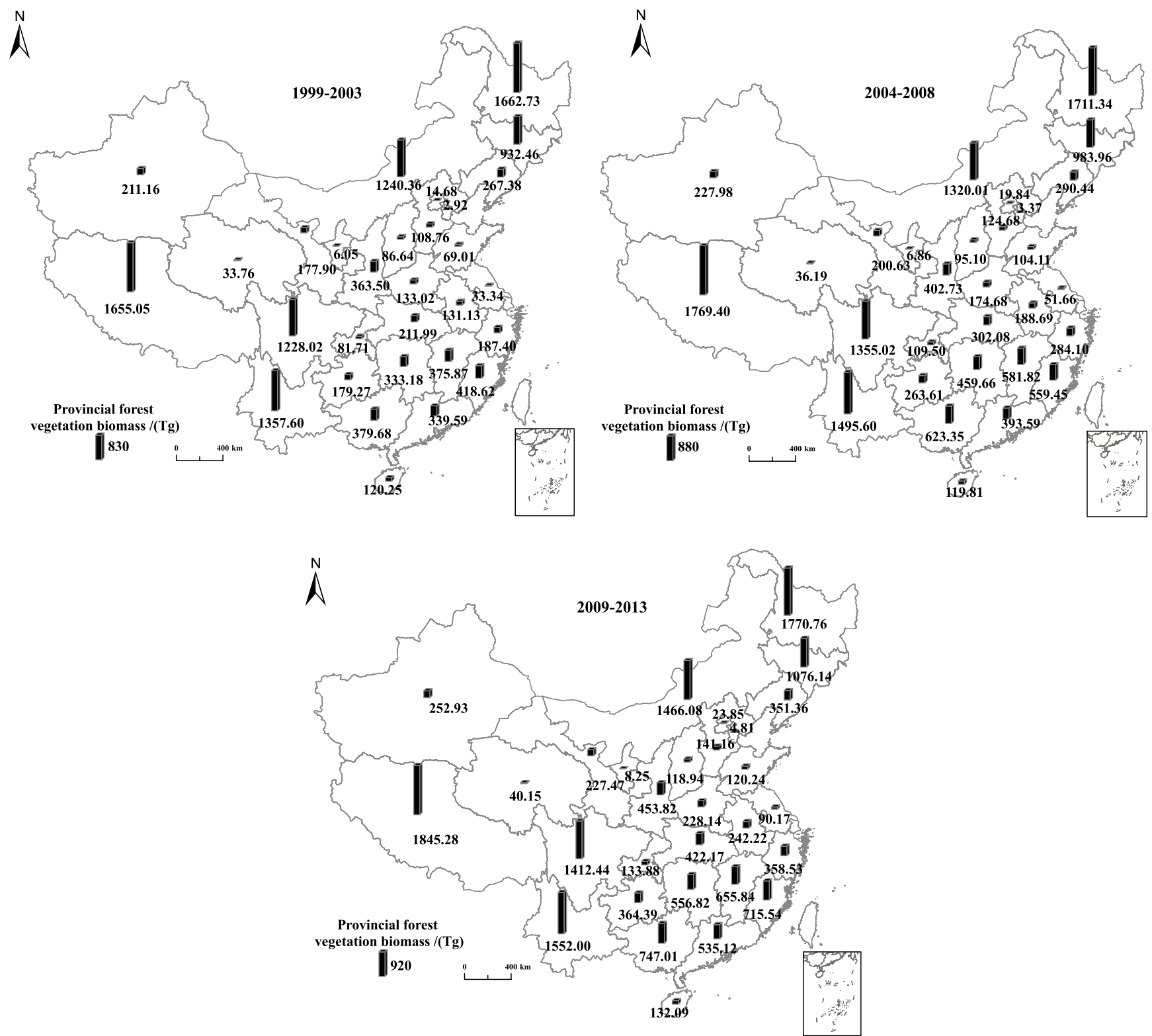

Fig. 3 Forest biomass at the provincial scale for the periods 1999-2003, 2004-2008 and 2009-2013. Due to high urbanization rate in Shanghai, forest area and volume are relatively small. In order to facilitate statistical calculation, Jiangsu and Shanghai were merged into Suhu regions

accounting for $11.9 \%$. Biomass greater than $1 \mathrm{Pg}$ occurred in Heilongjiang, Inner Mongolia, Tibet, Yunnan and Sichuan. The total biomass in northeast (4.3 Pg) and southwest (4.6 $\mathrm{Pg}$ ) was $8.9 \mathrm{Pg}$, accounting for $62 \%$ of the national total; for the $8^{\text {th }}$ forest inventory 2009-2013, the national total was $16.05 \mathrm{Pg}$, the highest of the three inventories. The highest biomass occurred in Tibet $(1.85 \mathrm{Pg})$ and accounted for $11.5 \%$ of the national total while the biomass in Heilongiang $(1.77 \mathrm{Pg}, 11 \%)$ was the second largest. Biomass in Heilongjiang, Inner Mongolia, Tibet, Yunnan, Sichuan and Jilin was greater than $1 \mathrm{Pg}$. The biomass in the northeast $(4.6 \mathrm{Pg})$ and southwest (4.8 Pg) was $9.4 \mathrm{Pg}$, accounting for $59 \%$ of the national total.

\section{Verification of forest biomass}

The provincial forest biomass obtained by the continuous BEF method was the premise for biomass downscaling and also the guarantee of the precision of the downscaling estimation. As a consequence, it was critical to verify the estimation results of the provincial biomass before the downscaling. Therefore, this study adopted the RE to compare with previous studies at national and provincial levels for the similar periods of time. 


\section{At the national scale}

The results show that RE between this study and previous studies were generally less than $20 \%$ (Table 2) (Xu et al. 2018a). It should be noted that differences in research methods, resolutions and data sources across studies may lead to substantial differences in results. Therefore, RE between results in this study and previous studies were reasonable at the national scale. That is, the precision of the method and forest biomass estimation were reasonable.

\section{At the provincial scale}

Relative errors were less than $20 \%$ at the provincial scale, which supports the conclusion that the results for the provincial scale and the accuracy of biomass estimation were rational (Table 3 ).

Table 2 Comparisons of forest biomass estimates in this study with previous studies at the national scale

\begin{tabular}{llll}
\hline $\begin{array}{l}\text { Total forest vegeta- } \\
\text { tion biomass (Pg) }\end{array}$ & RE & Study period & References \\
\hline 16.05 & - & $2009-2013$ & This study \\
17 & $5 \%$ & $2009-2013$ & Xu (2014) \\
14.06 & $14 \%$ & $2009-2013$ & Yu (2015) \\
14.26 & - & $2004-2008$ & This study \\
13.73 & $3.8 \%$ & $2004-2008$ & Guo et al. (2013) \\
15 & $4.9 \%$ & $2004-2008$ & Li et al. (2011a, b) \\
12.34 & - & $1999-2003$ & This study \\
12.58 & $1.9 \%$ & $1999-2003$ & Liu et al. (2012a, b) \\
11 & $12 \%$ & $1999-2003$ & Xu et al. (2007) \\
\hline
\end{tabular}

-indicates not applicable

\section{Downscaling of forest biomass}

\section{Spatial distribution of forest biomass}

This study took the 8th forest inventory as an example to implement the downscaling method and the 6th and 7 th inventories in the same way. The provincial statistics of influencing factors and the provincial forest biomass were standardized to facilitate the multiple regression analysis. Provincial mean values of temperature, precipitation, elevation and slope were incorporated into the regression along with the provincial cumulative value of NDVI. NDVI is an indicator of vegetation productivity, and forest biomass refers to the total amount of dry matter made up of living organisms. Therefore, we selected the cumulative value of NDVI into regression analysis. The provincial regression model was:

$Y=1.176 x_{1}+0.182 x_{2}-0.238 x_{3}+0.149 x_{4}+0.445 x_{5}-0.153$

where, the notation is the same as in Eq. 4. The model had a coefficient of determination $\left(R^{2}\right)$ of 0.85 and a $p<0.05$.

With these influencing factor layers standardized, the weight of biomass allocation can be formed by Eq. 9:

$S_{i j}=1.176 x_{1 i j}+0.182 x_{2 i j}-0.238 x_{3 i j}+0.149 x_{4 i j}+0.445 x_{5 i j}-0.153$

where, the notation is the same as in Eq. 5. Based on Eq. 6, we obtained the result of forest biomass at the pixel scale.

Based on the downscaling method, we estimated the spatial distribution of Chinese forest biomass from 1999 to 2013 with a resolution of $1 \mathrm{~km}$ (Fig. 4).

There are a few observations to note in Fig. 4 concerning the spatial distribution pattern of biomass. Firstly, biomass was generally found from the northeast to the southwest, which is consistent with the spatial distribution of water and heat conditions in China. Secondly, high forest biomass is

Table 3 Comparisons of forest biomass estimates in this study with previous studies at a provincial scale

\begin{tabular}{llllll}
\hline Province & \multicolumn{2}{l}{ Forest vegetation biomass $(\mathrm{Tg})$} & RE $(\%)$ & Study period & References \\
\cline { 2 - 4 } & This study & Previous studies & & & \\
\hline Inner Mongolia & 1466 & 1473 & 0.4 & 2015 & Huang et al. (2016) \\
Fujian & 418.62 & 396.02 & 5.7 & 2003 & Wang and Deng (2014) \\
Hunan & 556 & 601.4 & 7.5 & 2013 & Xia et al. (2017) \\
Tibet & 1845 & 1960 & 5.8 & 2011 & Yang et al. (2016) \\
Yunnan & 1552 & 1640 & 5.3 & 2012 & Yang et al. (2015) \\
Anhui & 242 & 204 & 18 & 2009 & Yu et al. (2015) \\
Henan & 133.02 & 111.54 & 19 & 2003 & Guang (2006) \\
Guangxi & 379.68 & 394.36 & 3.7 & 2000 & Han and Liang (2015) \\
Shaanxi & 453.82 & 476 & 4.7 & 2014 & Hao et al. (2017) \\
Beijing & 14.68 & 15.8 & 7 & 2000 & Zhang (2009) \\
\hline
\end{tabular}



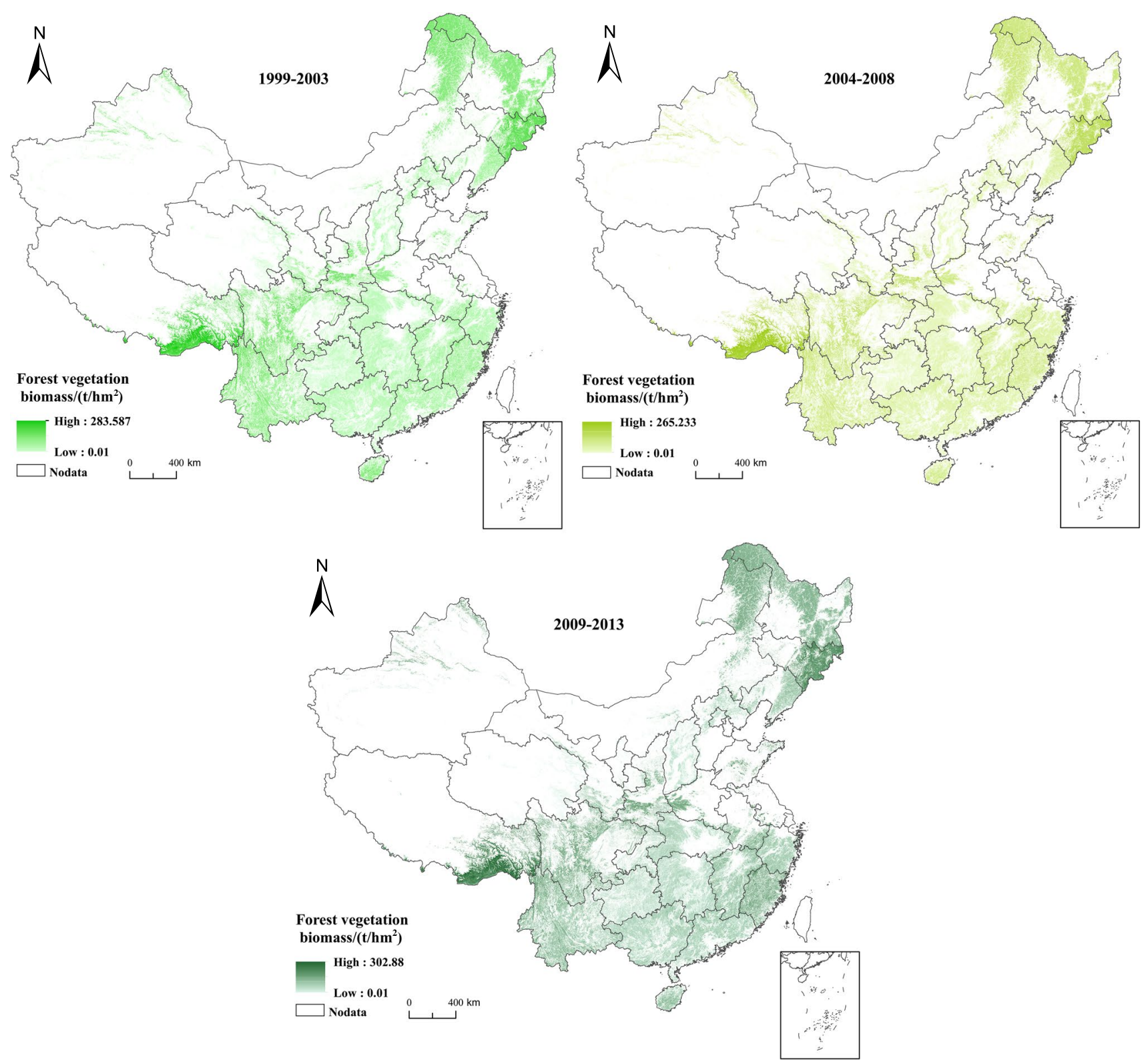

Fig. 4 Spatial distribution of forest biomass in China for the periods 1999-2003, 2004-2008 and 2009-2013

concentrated in the Da Hinggan Mountains, Xiao Hinggan Mountains and Changbai Mountains in the northeast, the Hengduan Mountains in the southwest, the Xinjiang Mountains areas (Altai Mountains, Tianshan Mountains, Kunlun Mountains) in the northwest, the Qinling Mountains in central China, and the Wuyi Mountains in the southeast. The major forest areas are in the northeast and southwest. Specifically, northeast China is high latitudes, with low annual average temperatures and with better water conditions so that forest cover is vast, organic matter decomposition rate is slow, and most forests are subalpine coniferous with large biomass. In addition, forests in northeast China are less likely to be affected by human activities. Southwest China is greatly affected by monsoons from the Indian Ocean, and northeast China is suitable for forest survival with abundant water and heat conditions. Natural forests are an important component of the total forest area in northeast China. Most of forests are coniferous with large biomass. Moreover, the region has complex terrain and therefore very little human disturbances.

\section{Verification of biomass gridding results}

Considering the scarcity of high-precision biomass data, it is difficult to verify the biomass gridding results from the pixel scale. Furthermore, taking the feasibility of the method and 
the availability of data into account, this study attempted to verify the biomass gridding results from the county scale (the county is the basic unit of the second type of forest inventory in China). This study synthesized pixel-based biomass at the county scale and compared it with previous studies for similar period of times (Table 4). The relative errors (RE) were less than $20 \%$. Therefore, the biomass gridding results were rational and the soundness of the downscaling method was acceptable.

\section{Spatio-temporal changes of forest biomass}

\section{At the national scale}

This study estimated total forest biomass based on forest inventory data, the spatio-temporal changes are shown in Table 5.

Total forest biomass increased from $12.34 \mathrm{Pg}$ during 1999-2003 to 14.26 Pg during 2004-2008, i.e., a net accumulation of $1.92 \mathrm{Pg}$ within five years with an annual increase of $0.38 \mathrm{Pg}$, and further increased to $16.05 \mathrm{Pg}$ during 2009-2013, i.e., a net increase of $1.79 \mathrm{Pg}$ within five years with an annual increase of $0.36 \mathrm{Pg}$ (Table 5). Overall, total forest biomass significantly increased from 1999 to 2013, approximately a net increase of $3.71 \mathrm{Pg}$ and an annual increase of $0.37 \mathrm{Pg}$. The results indicate that forest vegetation was a carbon sink during 1999-2013 in China. These findings are consistent with results of Fang et al. (2001; 2018) and others (Guo et al. 2013).

As the main component of a forest, most of the biomass was stored in standing timber. The biomass of forest stands was $11.48 \mathrm{Pg}$ from 1999 to 2003 , accounting for $93 \%$ of the total biomass in the same period, and it was $13.38 \mathrm{Pg}$ from 2004 to 2008, 15.11 Pg from 2009 to 2013, accounting for $93 \%$ and $94 \%$ of the total biomass, respectively, (Table 5). Stand biomass increased 1.90 Pg from 1999 to 2008 with an annual increase of $0.38 \mathrm{Pg}$, and $1.73 \mathrm{Pg}$ from 2004 to 2013 with an annual increase of $0.35 \mathrm{Pg}$. Overall, stand biomass increased continuously during 1999-2013 with a net gain of $3.63 \mathrm{Pg}$, contributing $98 \%$ of the annual increase in total forest biomass. Economic and bamboo forests showed no significant changes. Biomass of economic forests decreased at the beginning of the period and then increased, with an overall decrease of $0.02 \mathrm{Pg}$. Compared to economic forests, biomass of bamboo forests steadily increased at an annual rate of $0.01 \mathrm{Pg}$ per year with an overall net gain of $0.1 \mathrm{Pg}$.

\section{At the provincial scale}

Based on inventory data, forest biomass during 1999-2013 in individual provinces can be estimated, and the spatio-temporal changes of biomass can be illustrated (Fig. 5). Biomass varied greatly across provinces. From 1999 to 2008, biomass in all provinces increased except for Hainan. It increased most in Guangxi at 243.67 $\mathrm{Tg}$ and Jiangxi at 205.96 Tg, while it was only $-0.45 \mathrm{Tg}$ in Hainan. From 2004 to 2013, forest biomass in all provinces increased, specifically, most in Fujian at $156.08 \mathrm{Tg}$ and Inner Mongolia at $146.07 \mathrm{Tg}$. For the period 1999 to 2013, forest biomass in all provinces increased continuously. It increased most in Guangxi by $367.34 \mathrm{Tg}$ and Fujian by $296.92 \mathrm{Tg}$. These observations also demonstrate that forest vegetation in all provinces functioned as a carbon sink during the period 1999-2013.

\section{At a pixel scale}

Based on the spatial patterns of forest biomass mentioned above, the spatio-temporal changes of forest biomass at a pixel scale were estimated (Fig. 6). For 1999 to 2008, biomass in most parts of the country (94\%) was increasing; biomass loss (6\%) was primarily in Hainan, the Hengduan Mountains region and Northern Da Hinggan Mountains in the southwest and northeast. From 2004 to 2013, 89\% of forest biomass showed an increasing trend, and biomass
Table 4 Comparisons of biomass gridding results in this study with previous studies at the county scale

\begin{tabular}{lrllll}
\hline City and county & \multicolumn{2}{l}{$\begin{array}{l}\text { Forest vegetation biomass } \\
\text { (Tg) }\end{array}$} & RE (\%) & Study period & References \\
\cline { 2 - 3 } & This study & Previous studies & & & \\
\hline Anji, Zhejiang & 5.03 & 5.4 & 6.8 & 2012 & Zhao et al. (2017) \\
Shanghang, Fujian & 0.10 & 0.11 & 9 & 2002 & Zhang (2016) \\
Jiangle, Fujian & 13.39 & 11.8 & 13.5 & 2011 & Fang (2015) \\
Hulun Buir, Inner Mongolia & 892.58 & 1078 & 17.2 & 2010 & Wang et al. (2015) \\
Sishui, Shandong & 7.31 & 6.6 & 10.8 & 2015 & Cui et al. (2017) \\
Youyang, Hunan & 12.32 & 10.8 & 14.1 & 2011 & Zhao and Xie (2014) \\
Jianou, Fujian & 11.73 & 10.54 & 11.3 & 2007 & Li (2013) \\
Shaoguan, Guangdong & 63.46 & 67.8 & 6.4 & 2009 & Tan and Liang (2010) \\
Changdu,Tibet & 172.45 & 211.6 & 18.5 & 2015 & Ren et al. (2016) \\
Pingdingshan, Henan & 8.47 & 8.4 & 0.8 & 2008 & Peng et al. (2015) \\
\hline
\end{tabular}




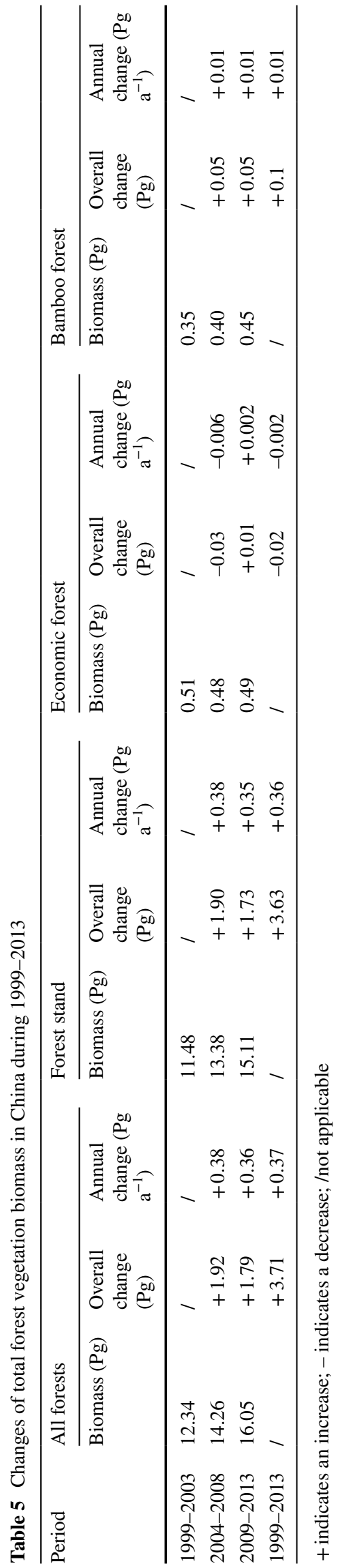

loss $(11 \%)$ mainly occurred in the southwest, including the southern areas of Tibet and east of Sichuan and Yunnan. From 1999 to 2013, there was an increasing trend in $97 \%$ of forest biomass with biomass loss (3\%) mainly in the Hengduan Mountains, in southern Hainan and in the northern Da Hinggan Mountains.

Statistics for forest biomass changes in individual provinces can be obtained as shown in Table 6 and Fig. 7. Both indicate the great variation in biomass across provinces. During 1999-2008, the total increase in biomass was 1967.89 $\mathrm{Tg}$, total reduction was $51.6 \mathrm{Tg}$, and net increase was $1916.29 \mathrm{Tg}$. Greatest losses occurred in Tibet $(10.8 \mathrm{Tg})$, Yunnan (10.19 Tg), Heilongjiang (7.66 Tg), Hainan (5.16 $\mathrm{Tg}$ ) and in Sichuan (3.87 Tg). During 2004-2013, the total increase in biomass was $1884.55 \mathrm{Tg}$, total reduction 96.27 $\mathrm{Tg}$, and net increase 1788.28 Tg. Considerable loss of forest biomass occurred in Tibet (39.26 Tg), Yunnan (22.25 Tg), Sichuan (13.94 Tg), Heilongjiang $(5.72 \mathrm{Tg}$ ) and in Xinjiang $(5.08 \mathrm{Tg})$. During 1999-2013, the total increase in biomass was $3732.89 \mathrm{Tg}$, the reduction was $28.32 \mathrm{Tg}$, and a net increase of $3704.57 \mathrm{Tg}$. The greatest loss of forest biomass occurred in Tibet at 11.14Tg, Heilongiiang at $7.73 \mathrm{Tg}$, Jilin at $2.39 \mathrm{Tg}$, Yunnan at $1.71 \mathrm{Tg}$ and in Sichuan at $1.7 \mathrm{Tg}$.

Thus the results indicate that decrease of forest biomass was more pronounced in the three southwest provinces (Tibet, Yunnan and Sichuan) and in Heilongjiang during the study period. The results of statistical analyses are consistent with the spatial distribution of changes in forest biomass noted previously.

\section{Discussion}

The provincial forest biomass estimated by the continuous BEF method is the basis of the downscaling method, which is also an external control, and the accuracy of the estimates directly affect the precision of the biomass estimates at a pixel scale. Although the continuous BEF method has been widely used in the estimation of biomass at a regional scale, owing to a vast territory, climate differences and variety of vegetation types in China, the method provides insufficient samples for particular forest types at a national scale (Pan et al. 2004; Zhao and Zhou 2004; Fang et al. 2007). IPCC methodology and a biomass regression model were adopted to estimate the biomass, and compared with that estimated by the continuous BEF method. The IPCC method is detailed in 2006 IPCC Guidelines for National Greenhouse Gas Inventory (https://www.ipcc.ch/report/2006-ipccguidelines-for-national-greenhouse-gas-inventories/), and the biomass regression model is based on Li and Lei (2010) and $\mathrm{Li}$ et al. (2012). The comparison results are shown in Table 7. It can be seen that the biomass estimates obtained by different methods are quite different, but all showed an 

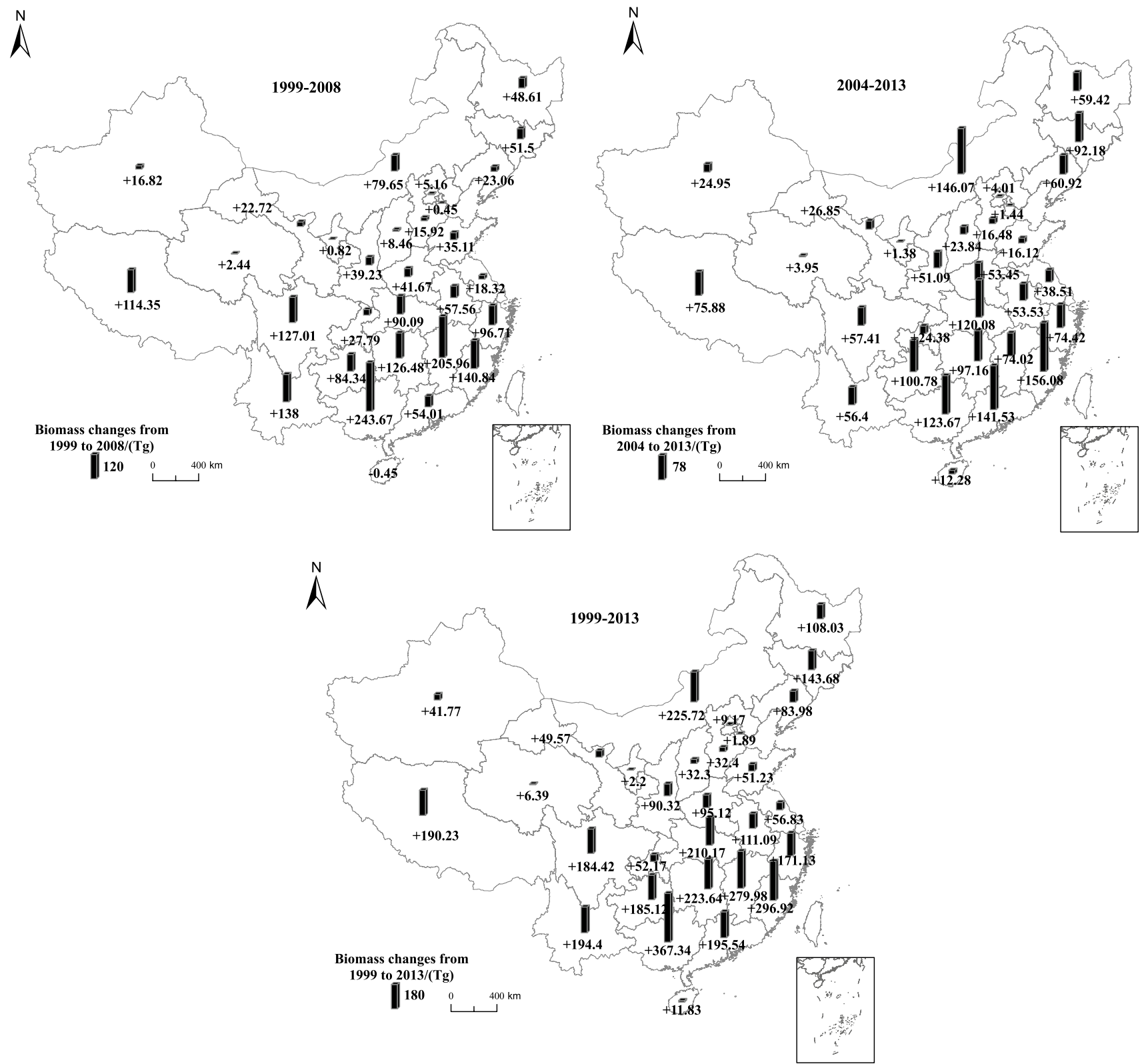

Fig. 5 Changes of forest biomass in provinces for the periods 19992008, 2004-2013 and 1999-2013; 1999-2008 indicates biomass changes from 6 to 7th forest inventory; 2004-2013 indicates biomass

increasing trend. Furthermore, the biomass estimated by the continuous BEF method was the highest, followed by that of the biomass regression model and the IPCC method. The continuous BEF method might not adequately consider the effect of age on biomass, resulting in a higher biomass value. Thus, the current biomass estimation methods were insufficient in universality and robustness. Thereby, improving the scientific and rational of biomass estimations, as well as the robustness of the method, should be the focus of follow-up research. More forest information (tree age, canopy spectra, textural property, and vertical structure parameters) might changes from 7 to 8th forest inventory; and 1999-2013 indicates biomass changes from 6 to 8th forest inventory; + indicates increase in biomass, - indicates decrease in biomass

be obtained quickly and accurately with the help of current remote sensing technology, and estimation models may be developed with higher accuracy and robustness by combining the field survey data.

Forest biomass is actually affected by several complex factors, such as natural changes (the rising density of $\mathrm{CO}_{2}$, forest fires, nitrogen deposition, extreme climates, plant diseases and insect pests) and human activities (forest management, reforestation and afforestation) (Liu et al. 2012a, b, 2020; Ali et al. 2020). Meanwhile, the effects of these factors on forest biomass are various. Among them, the 

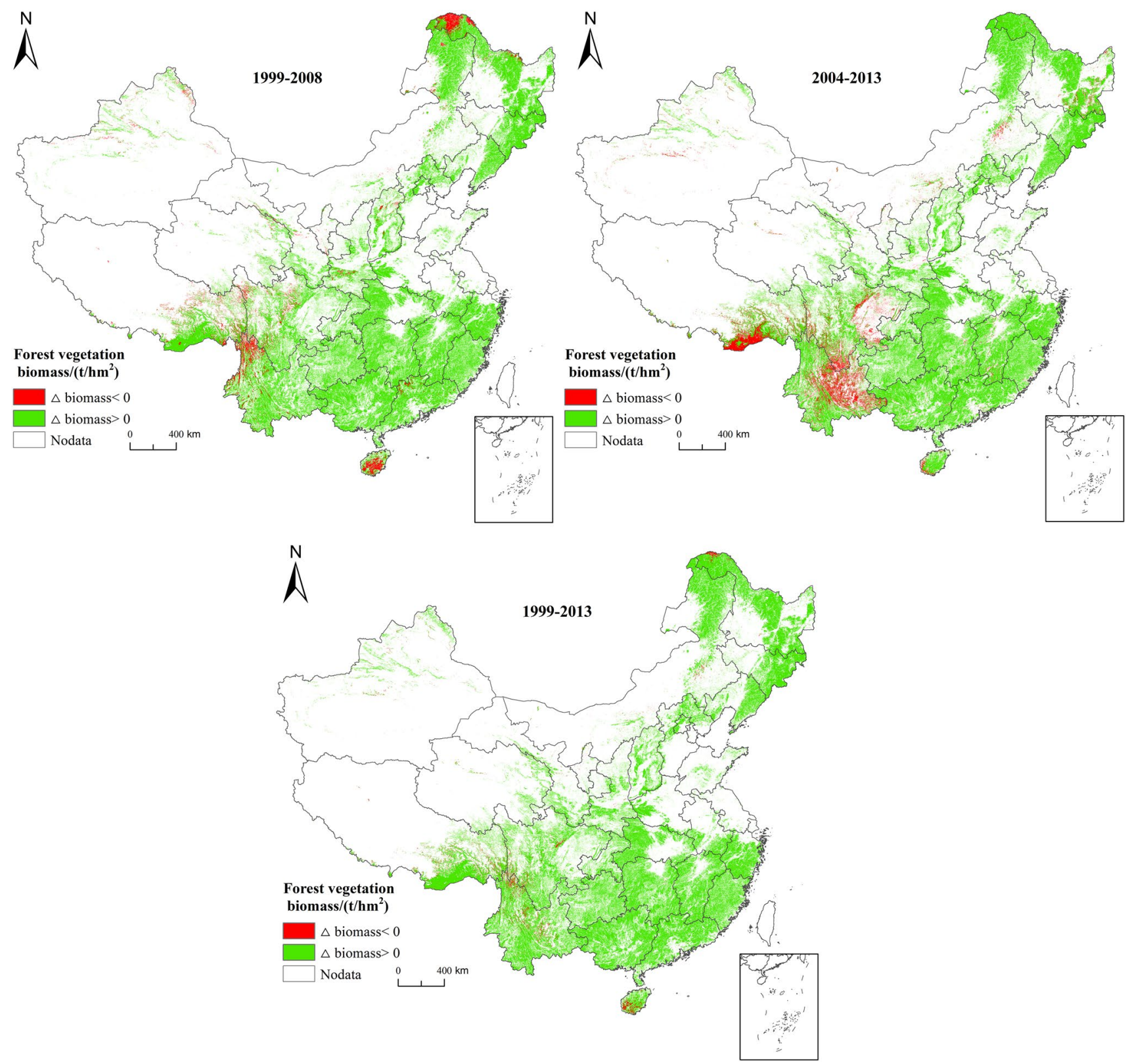

Fig. 6 Spatial distribution of forest biomass changes from 1999 to 2013 ; 1999-2008 indicates biomass changes from the 6th to 7th inventories, 2004-2013 from the 7th to 8th inventories, and 1999-

natural environment is the basic control of biomass change (Zhang 2011). Furthermore, forest biomass will be affected by human factors, and owing to the complexity of the effects of human factors on biomass, it was not possible to reflect human factors at a pixel scale in this study. As a consequence, considering the accessibility of the data, this study only selected the main natural factors without human factors, which needs to be further improved. In a follow-up study, we should attempt to extend and enrich data sources, and introduce human factors such as population density, planting practices, and artificial surface areas to build a more
2013 indicates changes from the 6th to 8th inventories; positive values represent the increase in biomass, while negative ones represent a decrease

comprehensive and statistical relationship between external variables and forest biomass, and further improve the accuracy of the downscaling method.

Remote sensing data (NDVI) were used in this study for long term dynamic monitoring of vegetation change. NDVI are usually obtained from different data sets, including SPOT vegetation, GIMMS, and MODIS. Some differences exist between sensors and the methods of interpreting data, whereby biomass estimations from different NDVI data sets might be different, which can lead to uncertainty at a pixel scale. Furthermore, forest areas used in this study 
Table 6 Statistics of forest biomass changes in each province for the periods 1999-2008, 2004-2013 and 1999-2013

\begin{tabular}{|c|c|c|c|c|c|c|}
\hline \multirow[t]{2}{*}{ Province } & \multicolumn{2}{|c|}{$\begin{array}{l}\text { Biomass changes from } 1999 \\
\text { to } 2008(\mathrm{Tg})\end{array}$} & \multicolumn{2}{|c|}{$\begin{array}{l}\text { Biomass changes from } 2004 \\
\text { to } 2013(\mathrm{Tg})\end{array}$} & \multicolumn{2}{|c|}{$\begin{array}{l}\text { Biomass changes from } \\
1999 \text { to } 2013(\mathrm{Tg})\end{array}$} \\
\hline & Increase & Decrease & Increase & Decrease & Increase & Decrease \\
\hline Heilongjiang & +56.27 & -7.66 & +65.14 & -5.72 & +115.76 & -7.73 \\
\hline Xinjiang & +17.27 & -0.45 & +30.03 & -5.08 & +41.91 & -0.14 \\
\hline Shanxi & +8.85 & -0.39 & +23.88 & -0.04 & +32.31 & -0.01 \\
\hline Ningxia & +0.96 & -0.14 & +1.41 & -0.03 & +2.26 & -0.06 \\
\hline Tibet & +125.15 & -10.8 & +115.14 & -39.26 & +201.37 & -11.14 \\
\hline Shandong & +35.11 & 0 & +16.63 & -0.51 & +51.30 & -0.07 \\
\hline Henan & +41.99 & -0.32 & +53.50 & -0.05 & +95.18 & -0.06 \\
\hline Anhui & +57.56 & 0 & +53.76 & -0.23 & +111.19 & -0.1 \\
\hline Hubei & +90.10 & -0.01 & +120.14 & -0.06 & +210.18 & -0.01 \\
\hline Zhejiang & +98.98 & -2.27 & +77.15 & -2.73 & +171.14 & -0.01 \\
\hline Jiangxi & +205.97 & -0.01 & +74.05 & -0.03 & +280.03 & -0.05 \\
\hline Hunan & +126.49 & -0.01 & +97.58 & -0.42 & +223.66 & -0.02 \\
\hline Yunnan & +148.19 & -10.19 & +78.65 & -22.25 & +196.11 & -1.71 \\
\hline Guizhou & +87.70 & -3.36 & +100.82 & -0.04 & +185.13 & -0.01 \\
\hline Fujian & +140.84 & 0 & +156.53 & -0.45 & +296.96 & -0.04 \\
\hline Guangxi & +243.67 & 0 & +124.02 & -0.35 & +367.35 & -0.01 \\
\hline Guangdong & +55.18 & -1.17 & +141.87 & -0.34 & +195.64 & -0.1 \\
\hline Hainan & +4.71 & -5.16 & +13.14 & -0.86 & +12.94 & -1.11 \\
\hline Jilin & +55.24 & -3.74 & +92.30 & -0.12 & +146.07 & -2.39 \\
\hline Liaoning & +23.10 & -0.04 & +61.02 & -0.1 & +84.04 & -0.06 \\
\hline Tianjin & +0.45 & 0 & +1.44 & 0 & +1.89 & 0 \\
\hline Qinghai & +2.58 & -0.14 & +4.45 & -0.5 & +6.88 & -0.49 \\
\hline Gansu & +23.04 & -0.32 & +27.16 & -0.31 & +49.74 & -0.17 \\
\hline Shaanxi & +39.52 & -0.29 & +51.54 & -0.45 & +90.40 & -0.08 \\
\hline Inner Mongolia & +80.89 & -1.24 & +147.84 & -1.77 & +226.29 & -0.57 \\
\hline Chongqing & +27.79 & 0 & +24.45 & -0.07 & +52.17 & 0 \\
\hline Hebei & +15.93 & -0.01 & +16.99 & -0.51 & +32.87 & -0.47 \\
\hline Beijing & +5.16 & 0 & +4.02 & -0.01 & +9.17 & 0 \\
\hline Sichuan & +130.88 & -3.87 & +71.35 & -13.94 & +186.12 & -1.7 \\
\hline Suhu & +18.33 & -0.01 & +38.55 & -0.04 & +56.84 & -0.01 \\
\hline Sum & +1967.89 & -51.6 & +1884.55 & -96.27 & +3732.89 & -28.32 \\
\hline
\end{tabular}

1999-2008 indicates biomass changes from 6 to 7th forest inventory; 2004-2013 indicates biomass changes from 7 to 8th forest inventory; 1999-2013 indicates biomass changes from 6 to 8th forest inventory; + indicates increase in biomass; - indicates decrease in biomass were derived from land use data and are quite different from the areas covered in the forest surveys. This certainly is of some influence on the estimation accuracy. In addition, the minimum canopy coverage in China's forest inventories is $20 \%$ and therefore forests with less than $20 \%$ canopy have been excluded. Considering that these low-canopy forests also play important roles in fixing $\mathrm{CO}_{2}$, such exclusion is unfortunate and needs to be assessed specifically in future. All these deficiencies are areas to be further promoted in subsequent research.

Ultimately the downscaling method based on the multiple regression relationship used in this study is commonly used, and is simple in form and adaptable (Maeaun et al.
2010). However, there are also some uncertainties. Firstly, the scale effect is sufficiently taken into account. The statistical relationships and coefficients estimated at a provincial scale were directly applied to the pixel scale, but the relationships among different scales and their effectiveness and stability remain to be settled. Secondly, the specific form of statistical relationship might vary with time and space, and may not be universal in all regions. Therefore, establishing targeted statistical relationships for specific study areas and periods should be considered. Generally, the scale effect and instability will influence the effectiveness of the downscaling method to a certain extent. Meanwhile, the uncertainty of the downscaling method is the focus of current research 
Fig. 7 Forest vegetation biomass changes by individual provinces in China during 1999-2013. 1999-2008 indicates biomass changes from 6 to 7th forest inventory; 2004-2013 indicates biomass changes from 7 to 8 th forest inventory; and 1999-2013 indicates biomass changes from 6 to 8 th forest inventory
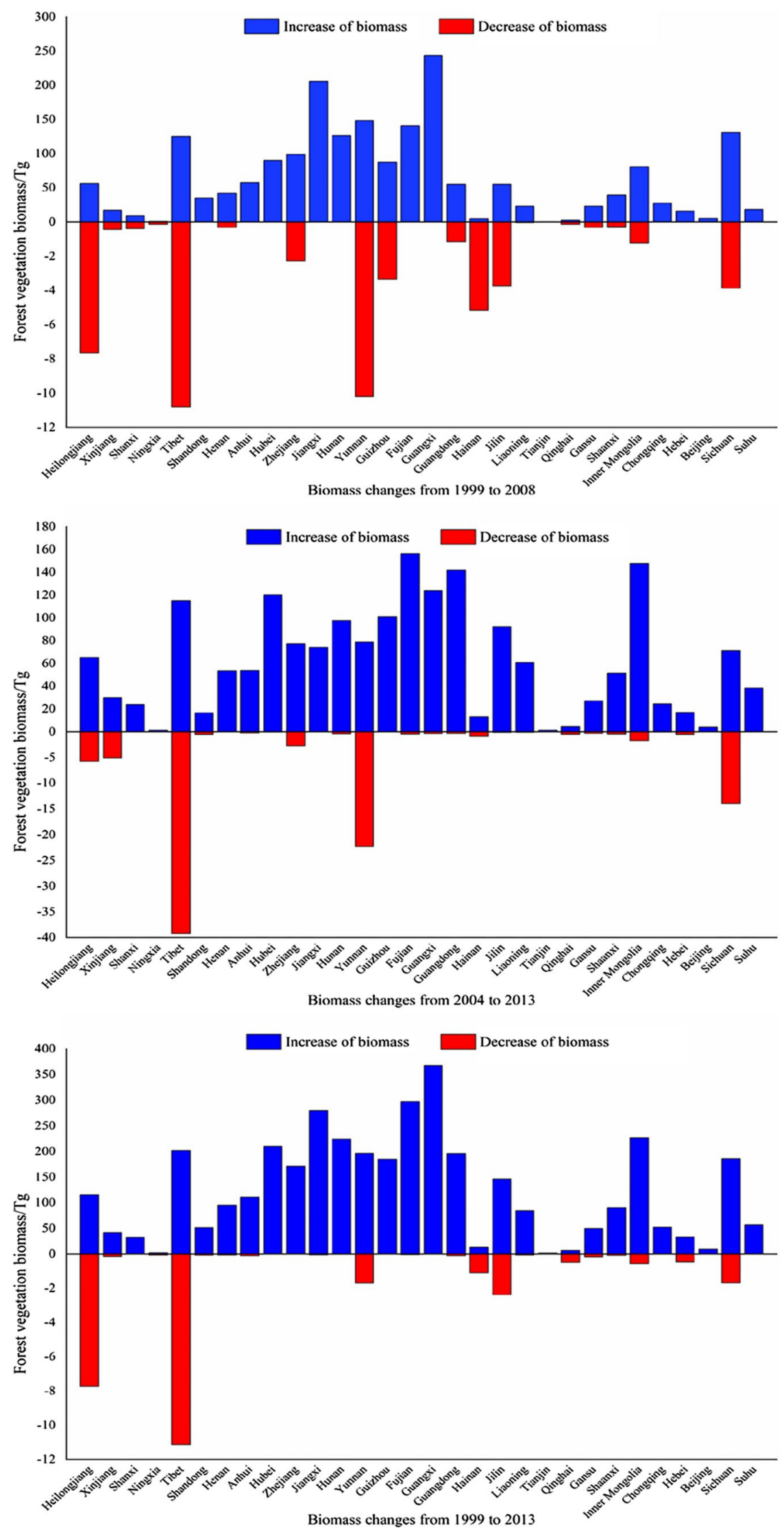
Table 7 Comparisons of biomass estimated by different methods

\begin{tabular}{llll}
\hline Study period & \multicolumn{3}{l}{ Total forest vegetation biomass $(\mathrm{Pg})$} \\
\cline { 2 - 4 } & $\begin{array}{l}\text { Continuous } \\
\text { BEF method }\end{array}$ & IPCC method & $\begin{array}{l}\text { Biomass } \\
\text { regression } \\
\text { model }\end{array}$ \\
\hline $1999-2003$ & 12.34 & 10.31 & 11.23 \\
$2004-2008$ & 14.26 & 11.10 & 12.45 \\
$2009-2013$ & 16.05 & 12.27 & 13.61 \\
\hline
\end{tabular}

(Wetterhall et al. 2006; Zhang et al. 2010). This study attempted to verify the external control of the downscaling method, i.e., provincial forest biomass, and the downscaling results, i.e., biomass gridding to certify the rationality of the method and the stability of the statistical relationship but this is insufficient. Therefore, it needs to be further improved in future studies such as trying to introduce more abundant variables (tree age, soil quality, human factors) to establish different statistical relationships, and to compare their reliability and applicability to determine the best method and reduce uncertainty.

\section{Conclusions}

With Chinese forest inventory data, this study explored the spatial distribution of forest biomass with a spatial resolution of $1 \mathrm{~km}$, and further analyzed spatio-temporal biomass changes by applying a downscaling method. The results show that it is feasible to estimate forest biomass at the pixel scale by employing forest inventory data, a regression model integrating multiple influencing factors, forest biomass at the provincial scale, and then a downscaling method. Moreover, forest biomass in China was in an obvious spatial distribution pattern from 1999 to 2013. Specifically, it was roughly divided by a line connecting northeast and southwest China. The highest forest biomass was concentrated in the Da Hinggan Mountains, Xiao Hinggan Mountains and Changbai Mountains in the northeast; in the Hengduan Mountains in the southwest; the Xinjiang Mountains areas (i.e., Altai Mountains, Tianshan Mountains and Kunlun Mountains) in the northwest; the Qinling Mountains areas in central China; and the Wuyi Mountains in southeast China. Forest biomass changes were also in a clear spatial distribution pattern. Increases (i.e., carbon sinks) mainly occurred in the east and southeast; decreases (i.e., carbon sources) mainly in the northeast to southwest. The greatest biomass losses occurred in the Hengduan Mountains, southern Hainan and in the northern Da Hinggan Mountains. Ultimately, forest vegetation in China functioned as a carbon sink over the period 1999-2013 and contributed a net increase in biomass of 3.71 Pg. China's efforts addressing ecological and environmental problems are not in vain and may be further supplemented and refined for better outcomes.

Open Access This article is licensed under a Creative Commons Attribution 4.0 International License, which permits use, sharing, adaptation, distribution and reproduction in any medium or format, as long as you give appropriate credit to the original author(s) and the source, provide a link to the Creative Commons licence, and indicate if changes were made. The images or other third party material in this article are included in the article's Creative Commons licence, unless indicated otherwise in a credit line to the material. If material is not included in the article's Creative Commons licence and your intended use is not permitted by statutory regulation or exceeds the permitted use, you will need to obtain permission directly from the copyright holder. To view a copy of this licence, visit http://creativecommons. org/licenses/by/4.0/.

\section{References}

Ali A, Sanaei A, Li MS, Nalivan OA, Ahmadaali K, Pour MJ, Valipour A, Karami J, Aminpour M, Kaboli H, Askari Y (2020) Impacts of climatic and edaphic factors on the diversity, structure and biomass of species-poor and structurally-complex forests. Sci Total Environ 706:135719

Austin KG, Baker JS, Sohngen BL, Wade CM, Daigneaulr A, Ohrel SB, Ragnauth S, Bean A (2020) The economic costs of planting, preserving, and managing the world's forests to mitigate climate change. Nature Commun 11:5946

Bonan GB (2008) Forests and climate change: forcings, feedbacks, and the climate benefits of forests. Science 320:1444-1449

Chen SL, Jiang H, Cai ZJ, Zhou XL, Peng CH (2018) The response of the net primary production of Moso bamboo forest to the on and Off-year management: a case study in Anji County, Zhejiang, China. For Ecol Manage 409:1-7

Cui CY, Li JH, Feng Y, Shi BD, Li XJ, Bian CB (2017) Estimations on carbon storage and carbon density of forest resources based on the county forest management inventory-the case of Sishui County. J Shandong AgricUniv 48(2):279-283 ((in Chinese))

Dixon RK, Solomon AM, Brown S, Houghton RA, Trexier MC, Wisniewski J (1994) Carbon pools and flux of global forest ecosystems. Science 263(5144):185-190

Ebermayer E (1876) Die gesamtelehre der waldstreumitrucksicht auf die chemischestatik des waldbaues. Springer, Berlin

Fang JY (2000) Forest productivity in China and its response to global climate change. ActaPhytoecologicaSinica 24(5):513-517 ((in Chinese))

Fang K (2015) Carbon stock dynamic of Jiangle County. Dissertation, Fujian Agriculture and Forestry University. (in Chinese)

Fang JY, Chen AP (2001) Dynamic forest biomass carbon pools in China and their significance. ActaBotanicaSinica 43(9):967-973 ((in Chinese))

Fang JY, Wang ZM (2001) Forest biomass estimation at regional and global level, with special reference to China's forest biomass. Ecol Res 16(3):587-592

Fang JY, Liu GH, Xu SL (1996) Biomass and net production of forest vegetation in China. ActaEcol Sin 16(5):497-508 ((in Chinese))

Fang JY, Chen AP, Peng CH, Zhao SQ, Ci LJ (2001) Changes in forest biomass carbon storage in China between 1949 and 1998. Science 292(5525):2320-2322

Fang JY, Chen AP, Zhao SQ, Ci LJ (2002) Estimating biomass carbon of China's forests: supplementary notes on report published in 
science (291:2320-2322) BY FANG et al. Acta Phytoecologica Sinica 26(2): 243-249. (in Chinese)

Fang JY, Guo ZD, Piao SL, Chen AP (2007) Terrestrial vegetation carbon sinks in China, 1981-2000 Science China Earth Sciences 50913411350 (in Chinese)

Fang JY, Zhu JL, Wang SP, Yue C, Shen HH (2011) Global warming, human-induced carbon emissions, and their uncertainties. Sci China Earth Sci 54(10):1458 ((in Chinese))

Fang JY, Yu GR, Liu LL, Hu SJ, Stuart CF (2018) Climate change, human impacts, and carbon sequestration in China. PNAS 115(16):4015-4020

FAO (2006) Global forest resources assessment 2005. FAO, Rome

Feng ZW, Chen CY, Zhang JW (1982) Determination of biomass of Pinus massoniana stand in Huitong county Hunan province. ScientiaSilvaeSinicae 18(2):127-134 ((in Chinese))

Guang ZY (2006) Study on forest biomass and productivity in Henan. J Henan AgricUniv 40(5):493-497 ((in Chinese))

Guo ZD, Fang JY, Pan YD, Birdsey R (2010) Inventory-based estimates of forest biomass carbon stocks in China: a comparison of three methods. For Ecol Manage 259(7):1225-1231

Guo ZD, Hu HF, Li P, Li NY, Fang JY (2013) Spatio-temporal changes in biomass carbon sinks in China's forests from 1977 to 2008. Sci China Life Sci 56(7):661-671 ((in Chinese))

Han MC, Liang YL (2015) Study on changes in forest biomass carbon storage based on forest inventory data in Guangxi. Forest ResourManag 6:111-116+122 ((in Chinese))

Hao L, Xu JJ, Xu Y, Li Y (2017) Forest carbon storage and its dynamic change in Shaanxi province in recent 30 years. Arid Zone Res 34(5):1056-1062 ((in Chinese))

Huang XQ, Xin CL, Hu ZM (2016) Carbon storage of the forests and its spatial pattern in Nei Mongol. China ActaPhytoecologicaSinica 40(4):327-340 ((in Chinese))

Kale MP, Roy PS (2012) Net primary productivity estimation and its relationship with tree diversity for tropical dry deciduous forests of central India. BiodiversConserv 21(5):1199-1214

Lal R (2008) Carbon sequestration. Philos Trans Royal Soc B BiolSci 363(1492):815-830

Li CW (2013) Dynamic change of forest carbon storage in Jian'ou city during 2003-2011. J BeihuaUniv 14(2):219-222 ((in Chinese))

Li HK, Lei YC (2010) Estimation and evaluation of forest biomass carbon storage in China. China Forestry Publishing House, Beijing ((in Chinese))

Li WH, Deng KM, Li F (1981) Biomass production of main ecosystems in Changbai Mountain. Forest Ecosyst Res 2(34):22

Li HK, Lei YC, Zeng WS (2011a) Forest carbon storage in China estimated using forestry inventory data. ScientiaSilvaeSinicae 47(7):7-12 ((in Chinese))

Li X, Ouyang XZ, Liu QH (2011b) Carbon storage of forest vegetation and its geographical pattern in China's Jiangxi province during 2001-2005. J Nat Resour 26(4):655-665 ((in Chinese))

Li HK, Zhao PX, Lei YC, Zeng WS (2012) Comparison of estimation of wood biomass using forest inventory data. ScientiaSilvaeSinicae 48(5):44-52 ((in Chinese))

Li F, Zeng Y, Li XS, Zhao QJ, Wu BF (2014) Remote sensing based monitoring of interannual variations in vegetation activity in China from 1982 to 2009. Sci China 57(8):1800-1806

Liao SB, Li ZH (2003) Study on spatialization of population census data based on relationship between population distribution and land use -taking Tibet as an example. J Nat Resour 18(6):659-665 ((in Chinese))

Liu QR, Sun R (2019) Spatial downscaling of forest biomass based on remote sensing. ActaEcol Sin 39(11):3967-3977 ((in Chinese))

Liu SN, Zhou T, Shu Y, Dai M, Wei LY, Zhang X (2012a) The estimating of the spatial distribution of forest biomass in China based on remote sensing and downscaling techniques. ActaEcol Sin 32(8):2320-2330 ((in Chinese))

Liu SN, Zhou T, Wei LY, Shu Y (2012b) The spatial distribution of forest carbon sinks and sources in China. ChinaSci Bull 57(14):1699-1707 ((in Chinese))

Liu L, Zeng FP, Song TQ, Wang KL, Du H (2020) Stand structure and abiotic factors modulate Karst Forest biomass in southwest China. Forests 11:443

Maeaun D, Wetterhall F, Ireson AM, Chandler RE, Kendon EJ, Widmann M, Brienen S, Rust HW, Sauter T, Theme $\beta 1$ M, Venema VKC, Chun KP, Goodess CM, Jones RG, Onof C, Vrac M, ThieleEich I (2010) Precipitation downscaling under climate change: recent developments to bridge the gap between dynamical models and the end user. Rev Geophys 43:1-34

Pan YD, Luo TX, Birdsey R, Hom J, Mellio J (2004) New estimates of carbon storage and sequestration in China's forests: effects of age-class and method on inventory-based carbon estimation. Clim Change 67(2-3):211-236

Peng SL, Liu DD, Chen CD, Zhao GQ (2015) Variation characteristics of forest carbon storage and carbon density in Pingdingshan city. GuizhouAgricSci 43(9):223-225 ((in Chinese))

Piao SL, Fang JY, Ciais P, Peylin P, Huang Y, Sitch S, Wang T (2010) The carbon balance of terrestrial ecosystems in China. Nature 458(7241):1009-1013

Quere CL, Moriarty R, Andrew RM, Canadell JG, Sitch S, Korsbakken JI, Firedlingstein P (2016) Global carbon budget 2015. Earth SystSci Data 7(2):521-610

Remezon NP (1999) Method studying the biological cycles of elements in forest. Soviet Soil Sci 1:59-67

Ren DZ, Ge LW, Wang RH, Zhang N, Pan G (2016) Carbon storage and spatial pattern of forest vegetation in Changdu. Tibet Chin J Ecol 35(4):903-908 ((in Chinese))

Tan WX, Liang SL (2010) Carbon storage of forest vegetation and its distribution in Shaoguan region of Guangdong province. Annual meeting of China association for science and technology, Fuzhou, China. 1994-2021 China Academic Journal Electronic Publishing House (C) pp 31-35. (in Chinese)

Tang XL, Zhao X, Bai YF, Tang ZY, Wang WT, Zhao YC, Wan HW, Xie ZQ, Shi XZ, Wu BF, Wang GX, Yan JH, Ma KP, Du S, Li SG, Han SJ, Ma YX, Hu HF, He NP, Yang YH, Han WX, He HL, Yu GR, Fang JY, Zhou GY (2018) Carbon pools in China's terrestrial ecosystems: new estimates based on an intensive field survey. PNAS 115(16):4021-4026

Tarun KT, Swamy SL, Arvind B, Mammohan JRD (2019) Assessment of biomass and net primary productivity of a dry tropical forest using geospatial technology. J For Res 30(01):157-170

Wan JZ, Wang CJ, Qu H, Liu R, Zhang ZX (2018) Vulnerability of forest vegetation to anthropogenic climate change in China. Sci Total Environ 621:1633-1641

Wang KD, Deng LY (2014) Dynamics of forest vegetation carbon stock in Fujian Province based on national forest inventories. J Fujian Coll For 34(2):145-151 ((in Chinese))

Wang WB, Jiang XL, Zhao PW (2015) Carbon storage in Hulunbeir area of inner Mongolia based on continuous forest inventory data. J Northeast For Univ 43(7):116-119 ((in Chinese))

Wang XC, Wang SD, Dai LM (2018) Estimating and mapping forest biomass in northeast China using joint forest resources inventory and remote sensing data. J For Res 29(03):797-811

Wetterhall F, Halldin S, Xu CY (2005) Statistical precipitation downscaling in central Sweden with the analogue method. J Hydrol 306(1-4):174-190

Wetterhall F, Bardossy A, Chen DL, Halldin S, Xu CY (2006) Daily precipitation-downscaling techniques in three Chinese regions. Water Resour Res 42(11):W11423

Woodwell GM, Whittaker RH (1978) The biota and the world carbon budget. Science 199(4325):141-146 
Xia S, Wang FS, Liu DK (2017) Changes of forest vegetation carbon storage in Hunan Province during 1999-2013. Hunan For SciTechnol 44(6):64-69 ((in Chinese))

$\mathrm{Xu}$ JD (2014) The 8th forest resources inventory results and analysis in China. For Econ 36(3):6-8 ((in Chinese))

Xu XL, Cao MK, Li KR (2007) Temporal-spatial dynamics of carbon storage of forest vegetation in China. ProgGeogr 26(6):1-10 ((in Chinese))

Xu SJ, Zeng B, Su XL, Lei ST, Liu JT (2012) Spatial distribution of vegetation and carbon density in Jinyun Mountain nature reserve based on RS/GIS. ActaEcol Sin 32(7):2174-2184 ((in Chinese))

Xu WY, Jin XB, Yang XH, Wang ZQ, Liu J, Wang D, Shan W, Zhou YK (2018b) The estimation of forest vegetation biomass in China in spatial grid. J Nat Resour 33(10):1725-1741 ((in Chinese))

Xu L, Shi YJ, Fang HY, Zhou GM, Xu XJ, Zhou YF, Tao JX, Ji BY, $\mathrm{Xu}$ J, Li C, Chen L (2018a) Vegetation carbon stocks driven by canopy density and forest age in subtropical forest ecosystems. Sci Total Environ 631-632:619-626

Yang T, Peng YH, Wang XK, Gong HD (2015) Estimation of carbon storage and density of forest ecosystem in Yunnan province. $\mathbf{J}$ West China For Sci 31(5):62-67 ((in Chinese))

Yang T, Peng YH, Wang XK, Su KW, Chen LH, Zhen W, Gong HD (2016) Estimation on carbon reserve and carbon density of the forest vegetation in five southwestern provinces. J Northwest For Univ 31(4):39-43 ((in Chinese))

Yu C (2015) Dynamic change of the biomass and net primary production for China based on national forest inventory. Dissertation, Anhui Agriculture University. (in Chinese)

Yu C, Wang B, Liu H, Zhang L, Yang XS, Xiu ZZ (2015) Dynamic change of forest biomass and net primary production of Anhui province during 1994-2013. Resour Environ Yangtze Basin 24:53-61 ((in Chinese))

Zhang P (2009) Study on forest carbon stock in Beijing of China. Dissertation, Beijing Forestry University. (in Chinese)
Zhang HY (2011) Forest biomass estimation and driving analysis of its changes in Zhangguangcai and Wanda Mountain. Dissertation, Northeast Forestry University. (in Chinese)

Zhang CG (2016) Estimating and dynamic change analysis of forest carbon storage in Shanghang County. Anhui AgricSci Bull 22(13): 108-110 ((in Chinese))

Zhang YG, Nearing MA, Zhang XC, Xie Y, Wei H (2010) Projected rainfall erosivity changes under climate change from multimodel and multiscenario projections in Northeast China. J Hydrol 384:97-106

Zhao T, Xie SY (2014) Distribution of forest carbon storage and carbon density based on GIS a case of Tujia and Miao autonomous counties in Youyang. Hubei AgricSci 53(3):553-557

Zhao FF, Xu ZX (2007) Comparative analysis on down scaled climate scenarios for head water catchment of Yellow River using SDS and delta methods. ActaMeteorologicaSinica 65(4):653-662 ((in Chinese))

Zhao M, Zhou GS (2004) Carbon storage of forest vegetation and its relationship with climatic factors. ScientiaGeographicaSinica 24(1):50-54 ((in Chinese))

Zhao MW, Yue TX, Zhao N, Sun XF (2013) Spatial distribution of forest vegetation carbon stock in China based on HASM. ActaGeograohicaSinica 68(09):1212-1224 ((in Chinese))

Zhao GQ, Zhao H, Feng SC (2017) Carbon storage characteristics of forest vegetation in Anji county of Zhejiang province. J Northwest For Univ 32(1):82-85 ((in Chinese))

Publisher's Note Springer Nature remains neutral with regard to jurisdictional claims in published maps and institutional affiliations. 